\title{
Corrosion Characteristics of Ascast Ductile Iron in Lime Juice
}

\author{
${ }^{* 1}$ F.O. Aramide, ${ }^{2}$ E.O. Olorunniwo, ${ }^{2}$ P.O. Atanda and ${ }^{1}$ J.O. Borode \\ ${ }^{1}$ Metallurgical and Materials Engineering Department, Federal University of Technology, \\ Akure, Ondo State, Nigeria. \\ 2 Materials Science and Engineering Department, Obafemi Awolowo University, Ile-Ife, \\ Osun State, Nigeria. \\ *Corresponding author : fat2003net@yahoo.com
}

\begin{abstract}
A study on the corrosion characteristics of ascast ductile iron in lime juice was conducted using the common weight loss method. Five standard tensile samples were prepared from the ascast condition of the alloy. One of them was taken to be for control, while the others were labeled A, $B, C$, and $D$. These labeled samples were then immersed in freshly extracted lime juice for a period of four weeks, having noted their respective initial weights. A sample was withdrawn from the medium at the end of each week for microstructural and tensile properties (using INSTRON 1195 at a fixed crosshead speed of $10 \mathrm{~mm} \mathrm{~min}^{-1}$ ) examination for comparison with those of the control sample. It was observed that the mechanical properties of the alloy were deteriorating due to pitting corrosion and that the corrosion rate increases with increase in the $\mathrm{pH}$ of the medium. It was concluded that corrosion rate can be kept to the minimum by controlling the $\mathrm{pH}$ of the media within the range 2.0 to 3.05 .
\end{abstract}

Keywords: Ductile iron; Corrosion rate; Pitting; Acidity; $p H$.

\section{INTRODUCTION}

Ductile Iron, also known as nodular iron or spheroid-graphite (SG) cast iron, was developed about 50 years ago as a substitute for steel. It contains nodules of graphite embedded in a matrix of ferrite or pearlite or both. The graphite separates out as nodules from iron during solidification because of the additives like cerium (Ce) and magnesium (Mg) introduced into the molten iron 
before casting [1, 2]. These nodules act as crack arresters thereby improving the mechanical properties of ductile iron [3,4]. The shape of the graphite present in an alloy affects the mechanical properties of the material. Flake graphite acts as a severe stress while the spherodical graphite does not. A classic example of this effect is the difference between gray and ductile cast iron [5].

Lime (Citrus aurantifolia) being an important agricultural product, has been used to prevent scurvy, a disease caused by a deficiency of vitamin C. Traditionally, lime has been used as a remedy for indigestion, heartburn and nausea. It also has cooling effects on fevers and can help ease coughs and various respiratory disorders $[6,7]$. To process this important product there is the need of selecting the material for designing and construction of machine that will give optimum service. While a lot is known on the effect of alloyed element on the mechanical properties of ductile cast iron [8, 9], not much is known of the corrosion characteristics of the ductile iron in lime juice. This is why this work focuses on the corrosion characteristics of ductile iron in lime juice.

\section{MATERIALS AND METHODS}

The ductile iron used in this work was procured from Engineering Materials Development Institute, Akure, Ondo State, Nigeria. The chemical composition of the ductile iron samples is shown in Table 1.

Table 1: Chemical Composition of the Ductile Iron Samples

\begin{tabular}{|c|c|}
\hline Element & Composition (\%) \\
\hline Manganese & 0.5 \\
\hline Carbon & 3.3 \\
\hline Silicon & 2.4 \\
\hline Sulphur & 0.02 \\
\hline Phosphorus & 0.003 \\
\hline Magnesium & 0.05 \\
\hline Iron & Balance \\
\hline
\end{tabular}

Five standard tensile specimens were prepared from the ductile iron sample using lathe machine. The machined tensile specimens were weighed on a digital balance and the initial weights were noted. The samples were labeled A to D with the remaining one being the control sample. Samples labeled A to D were immersed in freshly extracted lime juice which acted as corrosion medium. 


\subsection{Immersion Test}

The prepared specimens were weighed before immersed in lime juice inside a 500 -ml closed beaker. The duration of exposure to the corrosion medium was: 168, 336, 504 and 672 hours. After different duration times, the specimens were rinsed with distil water, dried, and weighed using digital balance type scaled (0.0001) to obtain the weight loss before and after immersion to calculate the corrosion rate using equation $[10,11,12,13]$ :

$$
R_{\text {cor }}=\frac{534 W}{D A T}
$$

Where:

$$
\begin{aligned}
& \text { W=weight loss }(\mathrm{g}) \\
& \mathrm{D}=\text { density of the materials }\left(\mathrm{g} / \mathrm{mm}^{3}\right) \\
& \mathrm{A}=\text { total surface area of the materials }\left(\mathrm{mm}^{2}\right) \\
& \mathrm{T}=\text { time of exposure in (hours) } \\
& \mathrm{R}_{\text {cor }}=\text { corrosion rate }(\mathrm{mm} / \mathrm{hr})
\end{aligned}
$$

The corroded tensile specimens in the corrosion media was removed at every seven days interval for further experimental investigations. This continued for four weeks.

\subsection{Tensile Testing}

In the present study, tensile tests were performed on INSTRON 1195 at a fixed crosshead speed of $10 \mathrm{~mm} \mathrm{~min}^{-1}$. Samples were prepared according to ASTM D412 (ASTM D412 1983) and tensile strength of standard and conditioned samples was calculated.

\section{RESULTS AND DISCUSSION}

Tables 2 shows the various tensile properties obtained for the samples as affected by the exposure time to the corrosion medium. These relationships were represented in Figures 1 to 6.

Figures 1 and 2 show the effects of exposure time on the specific weight loss and corrosion rate of the samples, respectively. From the Figure 1, it is seen that the samples were somehow resistant to corrosion within the first two weeks (336 hours). The specific weight loss was low even up to the third week, though there was the cumulative increase in the specific weight loss. Comparing Figures 1 and 2, it will be seen that the corrosion rate on the second week (336 hours) was lower than that of the first week (168 hours). This is attributed to the formation of a thin passive barrier film of hydrated oxides of silicon on the metal surface. The film develops with time due to the dissolution of iron from the metal matrix leaving behind silicon which 
hydrates due to the presence of moisture $[9,14]$. From the Figures, contrary to the common view; the corrosion rate increases with time of exposure; this could be because of the nature of the corrosion medium; the presence of carbohydrates, sugar and sodium in lime juice extract [15, $16,17]$ are contributing factors for the corrosion of these samples. These constituents are sources of oxygen which may increase the oxidation process in the medium thus promoting corrosion of the materials. But it is noteworthy that throughout the period of exposure, the corrosion rate was much lower than those recorded by other researchers [18].

Table 2: Effect of exposure time on the tensile properties of the samples

\begin{tabular}{|c|c|c|c|c|c|c|c|}
\hline Sample & $\begin{array}{c}\text { Exposure } \\
\text { Time } \\
(\mathrm{hrs})\end{array}$ & $\begin{array}{c}\text { Specific } \\
\text { Weight } \\
\text { Loss } \\
\left(\mathrm{g} / \mathrm{mm}^{2}\right) \\
\mathrm{X} \mathrm{10}^{-4}\end{array}$ & $\begin{array}{c}\mathrm{pH} \text { of } \\
\text { the } \\
\text { media }\end{array}$ & $\begin{array}{c}\text { Corrosion } \\
\text { Rate } \\
(\mathrm{mm} / \mathrm{hr})\end{array}$ & $\begin{array}{c}\text { Impact } \\
\text { Energy } \\
(\mathrm{J})\end{array}$ & Strain & $\begin{array}{c}\text { Ultimate } \\
\text { Tensile } \\
\text { Strength } \\
(\mathrm{Mpa})\end{array}$ \\
\hline Control & 0 & 0 & 2.00 & 0 & 2.06174 & 0.02368 & 250.4169 \\
\hline A & 168 & 45.91 & 2.72 & 0.00206 & 3.72212 & 0.03729 & 294.7923 \\
\hline B & 336 & 67.17 & 3.05 & 0.0015 & 2.92057 & 0.0369 & 213.5013 \\
\hline C & 504 & 294.37 & 3.30 & 0.00439 & 0.87385 & 0.01684 & 202.8675 \\
\hline D & 672 & 2740.91 & 4.46 & 0.0307 & 0.24029 & 0.01425 & 88.729 \\
\hline
\end{tabular}

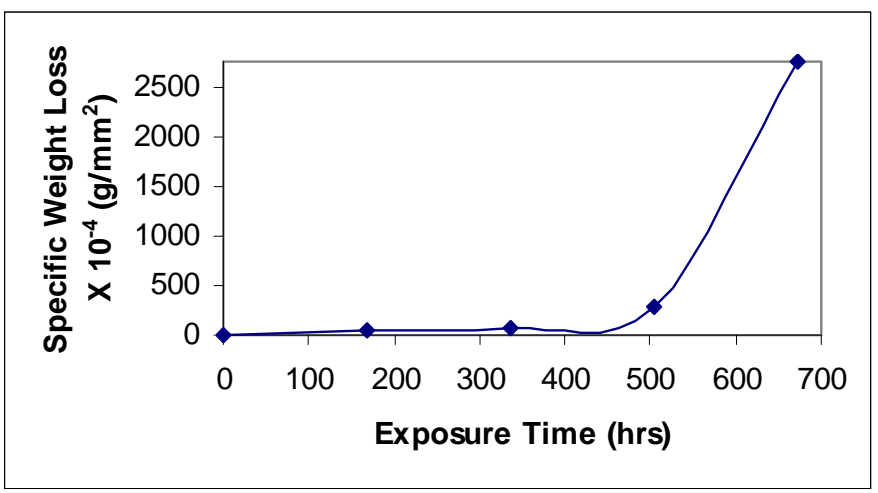

Figure 1 Effect of exposure time on the specific weight loss of the samples 


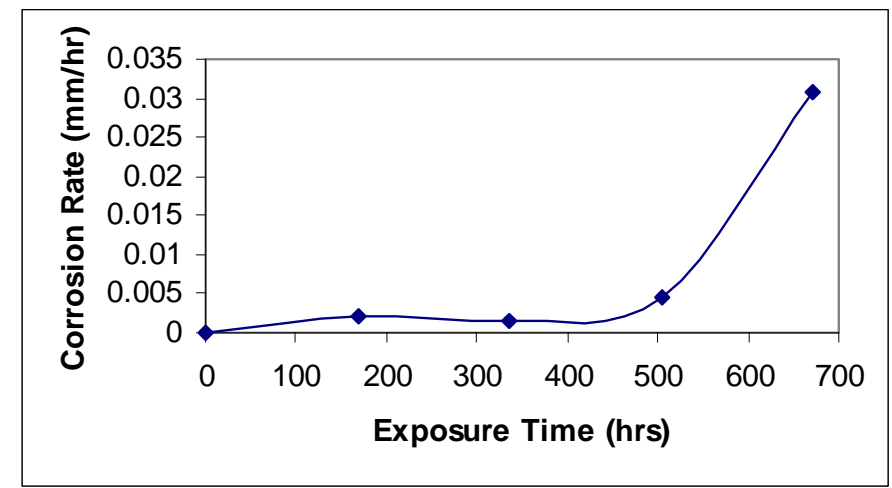

Figure 2 Effect of exposure time on the corrosion rate of the samples

Moreover, Figure 3 shows that the acidity of the corrosive media reduces as the exposure time increases. Comparing this with the situation in Figures 1 and 2, it can be said that the corrosion rate of the ductile iron samples increases with reduction in the acidity (or increase in the $\mathrm{pH}$ ) of the media. This reduction in the acidity of the media can not be considered to the resultant effect of the dissolution of iron or other consitituents of the ductile iron in the media; ofcourse, it is as a result of bio-deterioration which consists of complex conditions [19]. This can be an advantage to control the corrosion rate of the component moderating the $\mathrm{pH}$ of the surrounding medium; this is consistent with the findings of Bellanger and Rameau (1996) [20].

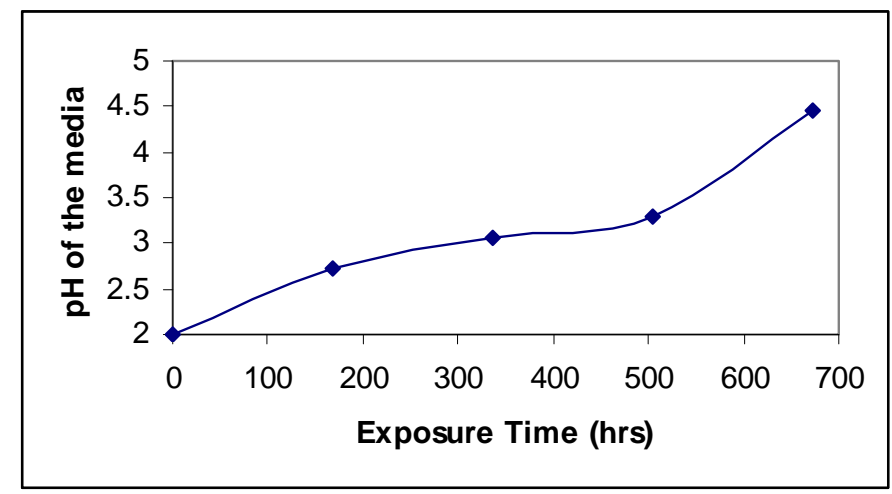

Figure 3 Variation in $\mathrm{pH}$ of the corrosion media with exposure time

From Figure 4 and 5, it is observed that both the energy at break and strain of the samples initially increased from what is obtainable in the as-cast condition (control) at the end of the first and second week, these properties thereafter decreased below that of the control sample. This could be because at the end of the second week some of the matrix metal has been leached off, thereby resulting into voids that resemble notches which are stress concentrator. This is further 
buttressed by the situation depicts in Figure 6; the ultimate tensile strength of the sample initially increased at the end of the first week, thereafter it decreased progressively.

Plate 1 shows the micrograph of the ascast ductile iron (control), while Plates 2 to 5 show the micrographs of the samples' surfaces exposed to the media (lime juice). Visual observation of the samples at the end of the first day revealed a progressive effervescence of gas giving out and the colour of the corroding media remain light green. However, by the first week all the samples had dull surfaces and all the corroding media had turned dark brown. Also micro cracks and pits were observed on the surface of the samples at the end of third week (Plates 6 and 7), indicating severe corrosion attack by the media, this attack became more pronounced on the sample at the end of fourth week.

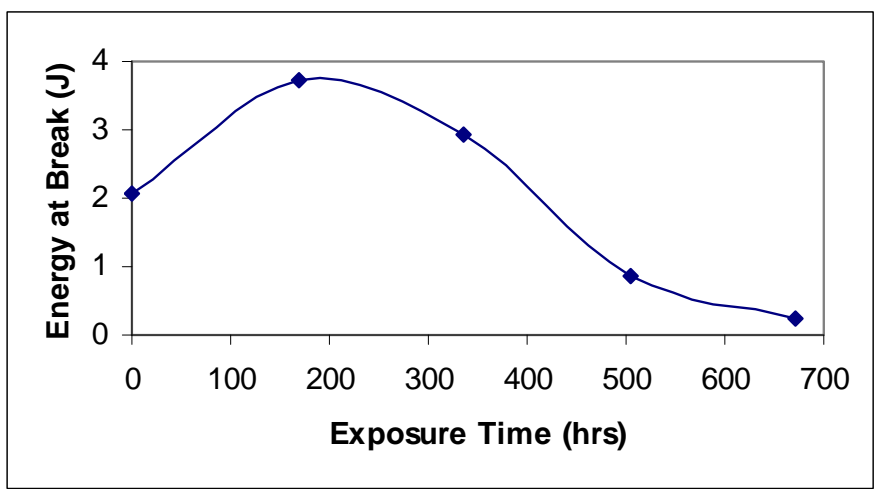

Figure 4 Effect of exposure time on the energy at break of the samples

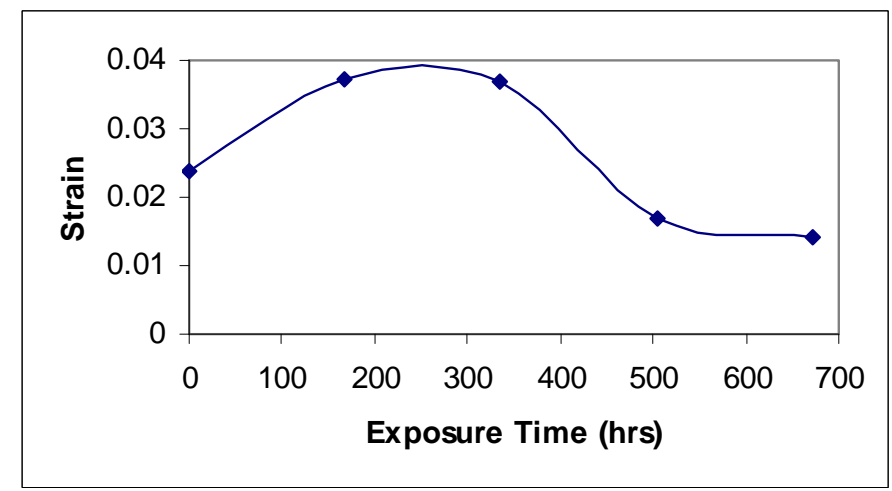

Figure 5 Effect of exposure time on the tensile strain of the samples 


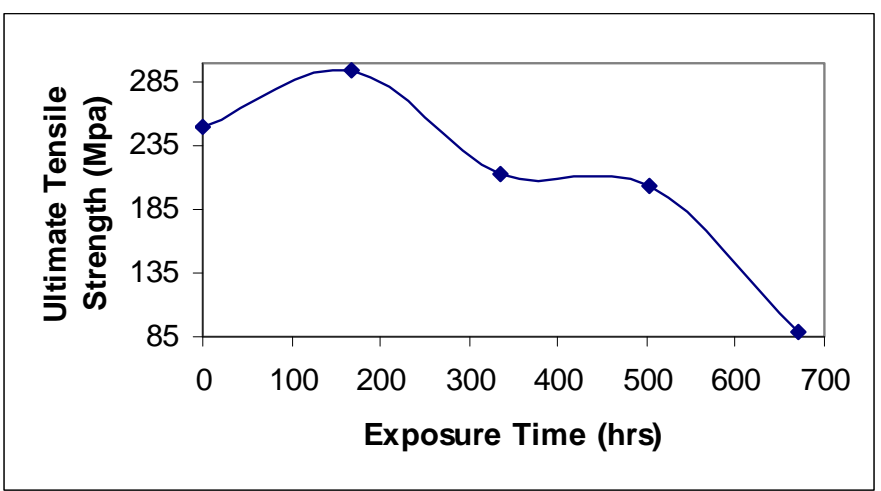

Figure 6 Effect of exposure time on the ultimate tensile strength of the samples

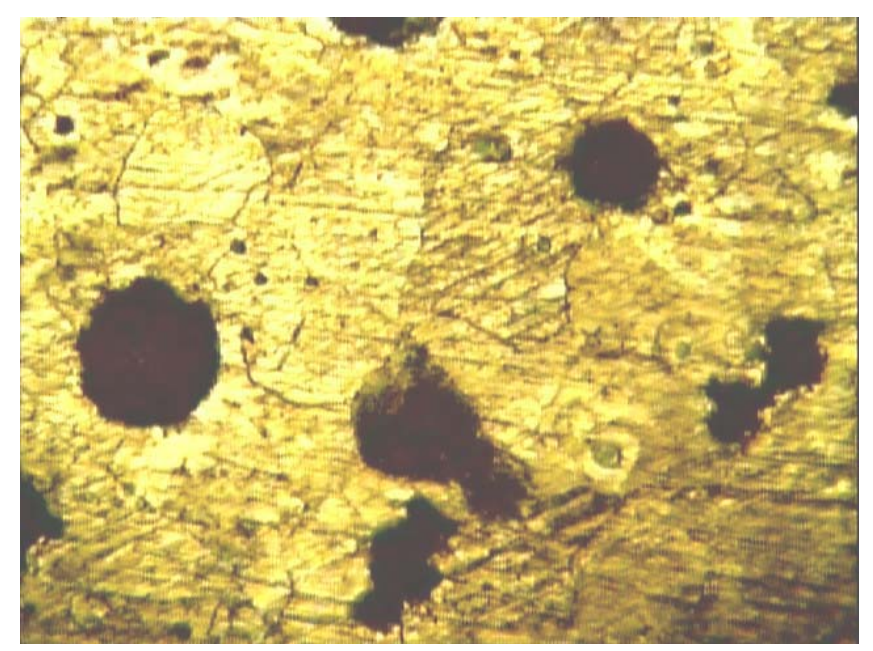

Plate 1 Micrograph of the ascast ductile iron sample

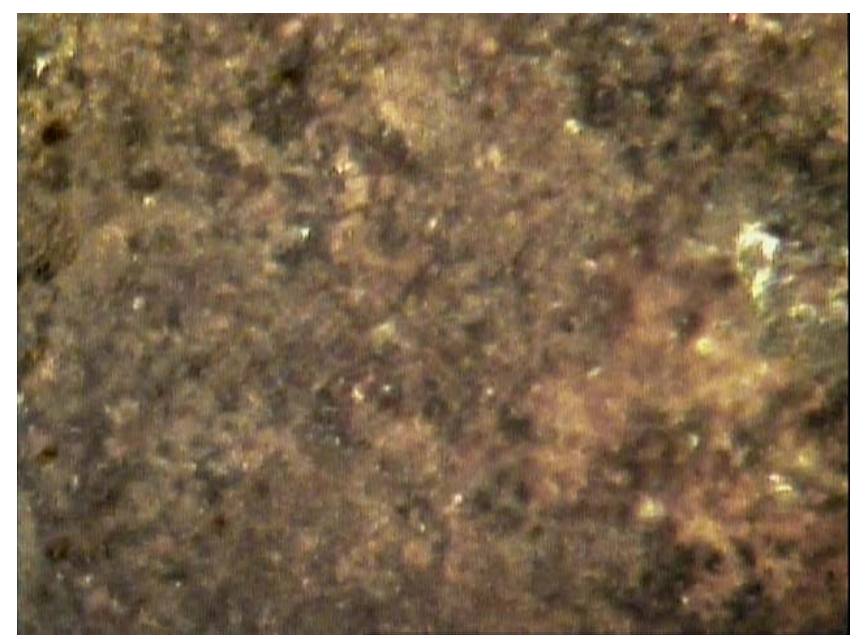

Plate 2 The corroded sample at the end of the first week (168 hours) 


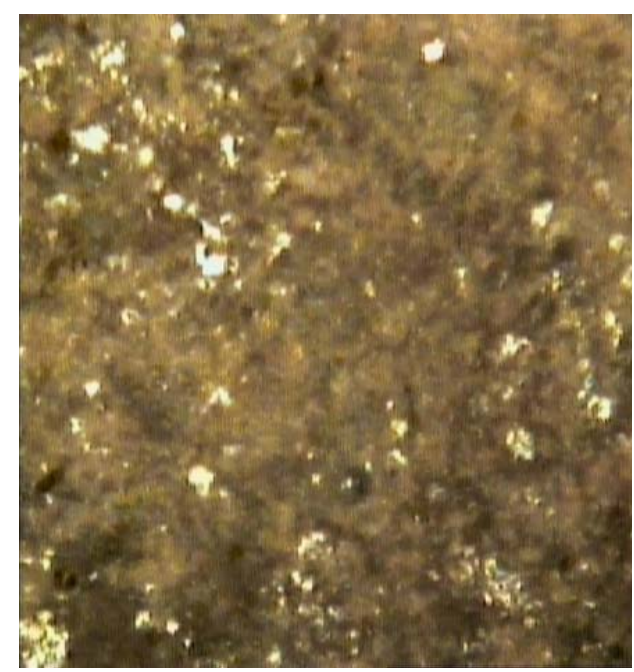

Plate 3 The corroded sample at the end of the second week (336 hours)

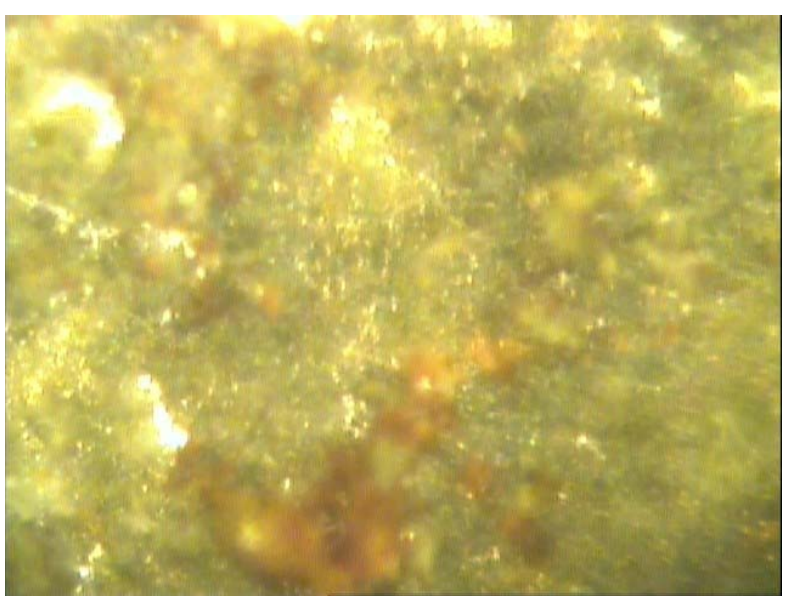

Plate 4 The corroded sample at the end of the third week (504 hours)

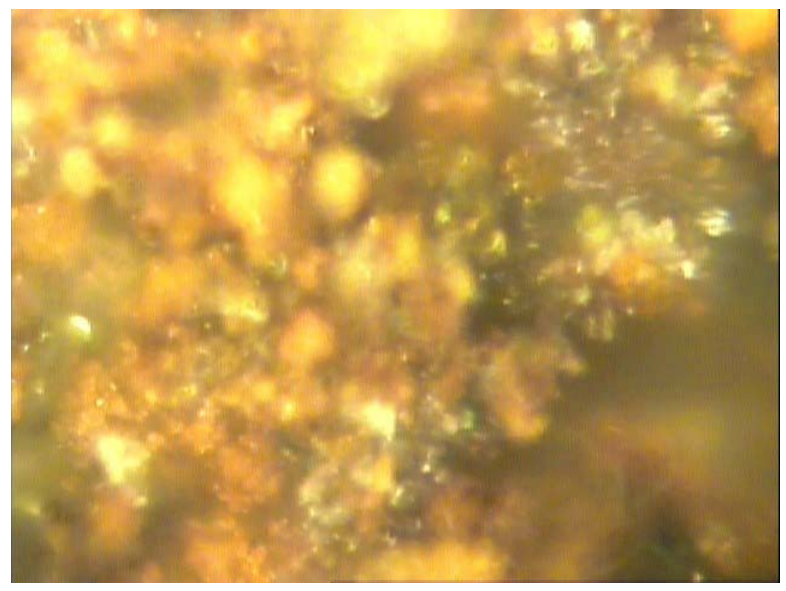

Plate 5 The corroded sample at the end of the fourth week (672 hours) 


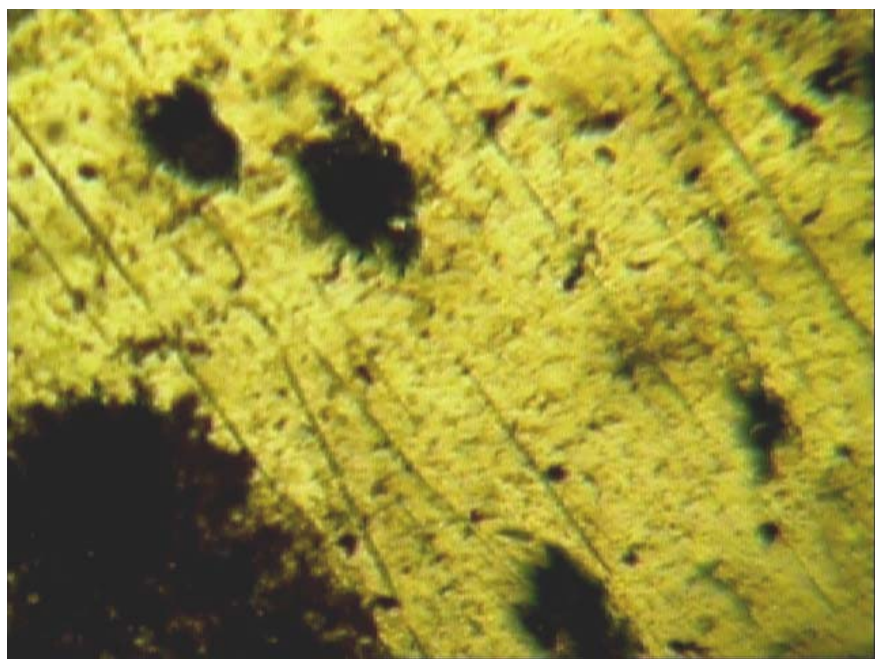

Plate 6 The corroded sample at the end of the third week (672 hours); showing pitting corrosion

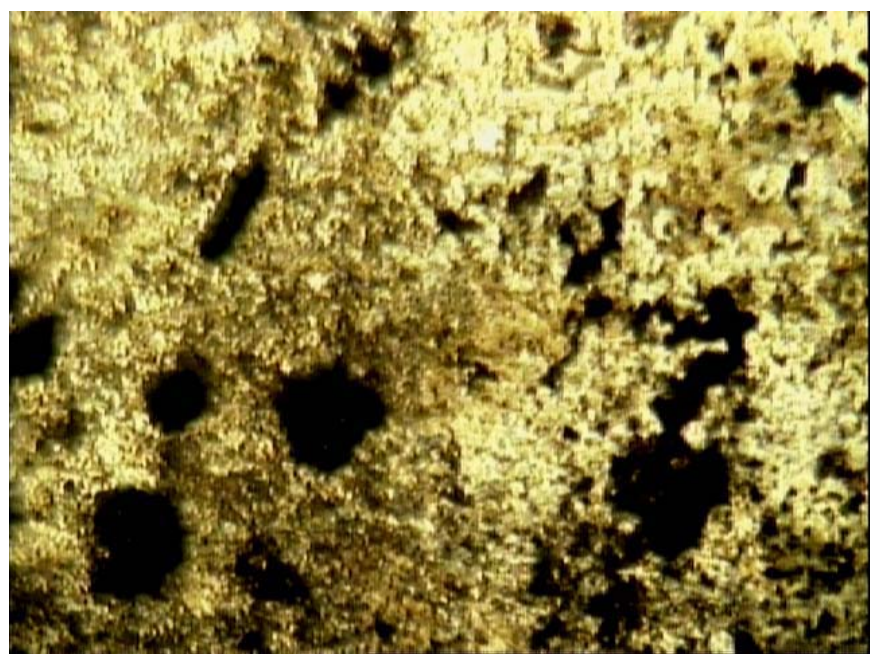

Plate 7 The corroded sample at the end of the fourth week (672 hours); showing pitting corrosion

\section{CONCLUSION}

From the discussion so far made it is concluded that:

- Corrosion deteriorates the mechanical properties of the ascast ductile iron

- Corrosion of ductile irons in lime juice is dependent on the $\mathrm{pH}$ of the medium; corrosion rate of ductile iron in lime juice increases with increase in the $\mathrm{pH}$ of the medium

- The corrosion of ductile iron in lime juice can be controlled by controlling the $\mathrm{pH}$ of the medium

- Keeping the $\mathrm{pH}$ of the medium between 2.0 and 3.05, the ascast ductile iron sample exhibits the best resistance to corrosion. 


\section{REFERENCE}

1. Aver, S.H., (1974); Introduction to physical metallurgy second edition McGraw-Hill Publishers, Londion pp: 146.

2. Prasanna, N. D. (2000); Effect of processes variables on the structure mechanical properties and wear characteristics of Austempred Ductile Iron, Ph.D thesis, submitted to Bangalore University, March 2000.

3. Allen, D.K., (1983); Metallurgy theory and practice, American technical society Chicago.

4. Grundy, R. (1979); The development and introduction of spheroidal graphite irons into an established range of malleable irons to meet current engineering requirements, Transactions of Foundrymen, Vol.72, Part-7, p141-151, July 1979.

5. ASTM Annual Book "Standard Specification for Automotive Gray Iron Casting “, A159-83, Vol. 0.1-0.2, (1986).

6. Morton, F.J., 1987. In Fruits of Warm Climates, 160-168, Creative Resource Systems, Inc., Winterville, N.C.

7. Chaisawadi, S., W. Methawiriyasilp, D. Thongbute and T. Chayawattana, 2005. Clean Production of Commercial Freeze-dried Lime Powder for Medicinal Herb and Nutritional Health Benefits. Acta Hort., (ISHS) 679: 29-35.

8. Venugopalan D. and A. Alagarsamy, 1990. "Effects of Alloy Additions on the Microstructure and Mechanical Properties of Commercial Ductile Iron." Transactions, American Foundrymen's Society, 98: 90-122.

9. George. A.N., 1960., Corrosion data, shell development Company, Emeryville Cardiff.

10. ASTM Annual Book "Standard Specification for Automotive Gray Iron Casting “, A159-83, Vol. 0.1-0.2, (1986).

11. Chen X. H., Chen C. S., Xiao H. N., Cheng F. Q., Zhang G., Yi G. J., Corrosion Behaviour of Carbon Nanotubes-Ni Composite Coating, Journal of Surface and Coating Technology 191, 2005, p. 351-356.

12. Ashassi-Sorkhabi H., Ghalebsaz- Jeddi N., Hashemzadeh F., Jahani H., Corrosion Inhibition of Carbon Steel in Hydrochloric Acid by Some Polyethylene Glycols, Journal of Electrochimica Acta 51, 2006, p. 3848-3854.

13. Jabeera B., Shibli S. M. A., Anirudhan T. S., Synergistic Inhibitive Effect of Tartarate and Tunstate in Preventing Steel Corrosion in Aqueous Media, Journal of Surface Science 252, 2006, p. 3520-3524.

14. Davies. D.J. and L.A. Oclmann,. 1983. The structures, properties and heat treatment of metals pitman books ltd, Publisher's.

15. http://practicalaction.org/docs/technical_information_service/lime_juice.pdf

16. Akindahunsi A. A., Oboh G., Oshodi A. A., Effect of Fermenting Cassava with Rhizopus Oryzae on the Chemical Composition of its Flour and Gari, Riv. Ital. Sostanze Grasse, 76, 1999, p. 437-440. 
17. Akindunmila F., Glatz B. A., Growth and Oil Production of Apiotrichum Curvatum in Tomato Juice, Journal of Food Protection, 6(11), 1998, p. 1515-1517.

18. Aigbodion, V.S., Mohammed, O.Y., Yakubu, S.I. and Agunsoye, J.O., Corrosion Characteristics of Vanadium Alloyed Ductile Cast Iron in Nitric Acid, Journal of Applied Sciences Research, 4(10): 1267-1271, 2007

19. Solomon, S. Post-harvest deterioration of sugarcane, Journal of Sugar Technology, 11(2), 109-123, 2009.

20. Bellanger, G. and Rameau, J.J. Effect of slightly acid pH with or without chloride in radioactive water on the corrosion of maraging steel, Journal of Nuclear Materials, 228(1), 224-37, 1996. 